\title{
The Immediate Results of Surgical Treatment of Bladder Cancer
}

\author{
Alexei L. Charyshkin, PhD, ScD ${ }^{1}$; Denis A. Matorkin²; Vladimir P. Demin, ${ }^{2} D^{1}$ \\ Institute of Medicine, Ecology and Physical Education of Ulyanovsk State University, Ulyanovsk \\ ${ }^{2}$ Lipetsk Regional Oncology Center, Lipetsk \\ The Russian Federation
}

\begin{abstract}
The objective of this study was to evaluate the immediate results of the use of ureterointestinal anastomosis according to the Bricker technique at radical cystectomy (RC) for bladder cancer (BC).

Materials and Results: The study included 96 patients (11.5\% women and $88.5 \%$ men) with BC, aged from 31 to 74 years (mean age 63.8 7.2), who underwent RC in the Lipetsk Regional Oncology Center, in the period from 2005 to 2014.

Among the early postoperative complications, we identified dynamic ileus (16.7\%), inflammatory complications of the surgical wound $(12.5 \%)$, acute pyelonephritis $(10.4 \%)$, and failure of ureterointestinal anastomosis $(4.2 \%)$. The frequency of postoperative acute pyelonephritis corresponded to the findings of other authors. Two $(2.1 \%)$ patients died from early postoperative complications because of concomitant diseases (ischemic heart disease, myocardial infarction); thus, postoperative mortality in the early postoperative period was $4.2 \%$. Chronic pyelonephritis with chronic renal failure detected in $15(15.6 \%)$ patients after one year after surgery was the most frequent late postoperative complication. The stricture of ureterointestinal anastomosis in $9(9.4 \%)$ patients has been eliminated through relaparotomy and resection of anastomosis. The development of urolithiasis in $12(12.5 \%)$ patients after one year after surgery has required the implementation of contact lithotripsy and litholytic therapy. (Int $\mathbf{J}$ Biomed. 2016;6(2):110-113.).
\end{abstract}

Key Words: bladder cancer • radical cystectomy• ureterointestinal anastomosis• postoperative complications

\section{Introduction}

Currently, malignant neoplasm of the bladder is a frequent urinary tract malignancy. In the entire structure of cancer pathology in Russia, bladder cancer is diagnosed in $4.5 \%$ of men and $1 \%$ of women. ${ }^{[1-3]}$ Mortality in patients with $\mathrm{BC}$ in Russia remains high and exceeds global mortality by $19.8 \% \cdot{ }^{[1-3]}$ In $45 \%$ of patients, $\mathrm{BC}$ is found in the early stages. The annual global BC incidence reached up to 335.8 thousand people. ${ }^{[2-8]}$ Malignant transformation of the urothelium occurs at disturbances of molecular interactions that regulate cellular homeostasis. ${ }^{[1,2,9-12]}$ One of the main risk factors for bladder cancer is a genetic predisposition..$^{[1,2,13,14]}$ A number of studies have identified numerous genetic changes, which, directly or indirectly, contribute to the formation of bladder tumors..$^{[1-3,15-17]}$

*Corresponding author: Prof. Alexei L. Charyshkin, PhD, $S c D$, Head of the Faculty Surgery Department, Institute of Medicine, Ecology and Physical Education of the Ulyanovsk State University. Ulyanovsk, the Russian Federation.E-mail: charyshkin@yandex.ru
In modern oncology, radical cystectomy is the standard treatment for muscle invasive bladder cancer. ${ }^{[1-3,16]}$ According to statistics, $57 \%$ of patients who underwent RC had a primary muscle invasion. ${ }^{[1-3]}$ About $30 \%$ of patients with muscle invasive bladder cancer at the time of disease detection have undiagnosed distant metastases, and $25 \%$ of patients receive radical surgical treatment at already existing lesions of the lymph nodes. ${ }^{[13,14,18]}$

Radical cystectomy involves complete removal of the bladder with lymph node dissection. Pelvic lymphadenectomy can reduce the risk of local recurrence and potentially improve a cancer-specific survival. According to the literature, an extended pelvic lymphadenectomy has a prognostic advantage compared to the standard lymphadenectomy for bladder cancer. $^{[1-5,16]}$

Radical cystectomy is one of the most traumatic operations, so that the risk of early and late postoperative complications is high. ${ }^{[1-3,18]}$ Choosing the best treatment options for patients with this pathology still remains one of the most complex and controversial issues among the various surgical schools and directions. 
The main objective of our study was to evaluate the immediate results of the use of ureterointestinal anastomosis according to the Bricker technique at radical cystectomy for bladder cancer.

\section{Materials and Methods}

The study was retrospective, controlled, and nonrandomized. The number of patients for primary selection was 706; the number of patients included in the subsequent analysis was 96 . Inclusion criteria were age 31 years and older, male and female, stage I-III muscle-invasive bladder cancer, a radical cystectomy. Exclusion criteria were myocardial infarction and acute cerebrovascular accident.

All 96 patients ( $11.5 \%$ women and $88.5 \%$ men) with bladder cancer, aged from 31 to 74 years (mean age 63.8 $8 \pm 7.2$ ), underwent radical cystectomy in the Lipetsk Regional Oncology Center, in the period from 2005 to 2014. Baseline demographic characteristics of patients enrolled in this study are presented in Table 1.

All patients were examined according to treatmentdiagnostic standards. This examination included general clinical, laboratory and special instrumental investigations (X-ray, endoscopy, ultrasound, histological research methods). If necessary, we perform echocardiography, ultrasound examination of abdominal cavity and retroperitoneal space.

Table 1.

Baseline demographic characteristics of patients

\begin{tabular}{|l|c|c|c|}
\hline \multirow{2}{*}{$\begin{array}{c}\text { Age } \\
(\mathrm{y})\end{array}$} & \multicolumn{2}{|c|}{ Gender } & \multirow{2}{*}{$\begin{array}{c}\text { Number of } \\
\text { patients }\end{array}$} \\
\cline { 2 - 4 } & Male & Female & $2(2.1 \%)$ \\
\hline $31-40$ & $2(2.1 \%)$ & - & $9(9.4 \%)$ \\
\hline $41-50$ & $7(7.3 \%)$ & $2(2.1 \%)$ & $32(33.3 \%)$ \\
\hline $51-60$ & $28(29.1 \%)$ & $4(4.2 \%)$ & $33(34.4 \%)$ \\
\hline $61-70$ & $29(30.2 \%)$ & $4(4.2 \%)$ & $30)$ \\
\hline$\geq 71$ & $19(19.8 \%)$ & $1(1.0 \%)$ & $20(20.8 \%)$ \\
\hline Total & $85(88.5 \%)$ & $11(11.5 \%)$ & $96(100 \%)$ \\
\hline
\end{tabular}

Ureterointestinal anastomosis was performed according to the Bricker technique: The urethras were crossed in their lower third and intubated with corresponding diameter drains. A mobilization of ileum site with a length of $30 \mathrm{~cm}$ to $40 \mathrm{~cm}$ was performed. The integrity of the intestinal tract was restored by anastomosis between the proximal and distal ends of the intestine. A single-row anastomosis was imposed between the urethra distal end and the intestine wall - "end-to-side." A urostomy was formed in the abdominal wall.

Evaluation of the functional condition of the kidneys and urinary tract in the early and late postoperative periods was carried out on the basis of a comprehensive examination, including the assessment of the level of serum creatinine, electrolytes, acid-base balance of blood, ultrasonography of the upper and lower urinary tract, excretory urography, renoscintigraphy, retrograde and antegrade pyelography with the Whitaker test, computed tomography of the abdomen and pelvis, complex urodynamic study and cysto- and ureteroscopy if it is required.

The study was conducted in accordance with ethical principles of the Declaration of Helsinki. It was approved by the by Ethics Committee at the Lipetsk Regional Oncology Center. Written informed consent was obtained from all participants. Statistical analysis was performed using the statistical software «Statistica». (v6.0, StatSoft, USA).

\section{Results and Discussion}

Among the early postoperative complications, we identified dynamic ileus (16.7\%), inflammatory complications of the surgical wound (12.5\%), acute pyelonephritis (10.4\%), and failure of ureterointestinal anastomosis (4.2\%). It should be noted that the dynamic ileus was the most common complication among the early postoperative complications (Table 2). The treatment of this complication included installation of a nasogastric tube to evacuate the stomach contents, prolonged epidural anesthesia, bowel stimulation, cleansing enemas, and infusion therapy. The failure of ureterointestinal anastomosis was found in 4(4.2\%) patients; in these cases we conducted relaparotomy, sanitation, and drainage of the abdominal cavity, and then after closing, anastomotic defect drains were removed.

\section{Table 2.}

Early postoperative complications in patients with bladder cancer $(n=96)$ in the period from 2005 to 2014

\begin{tabular}{|l|c|}
\hline \multicolumn{1}{|c|}{ Early postoperative complications } & $\begin{array}{c}\text { Number of } \\
\text { patients }\end{array}$ \\
\hline Dynamic ileus & $16(16.7 \%)$ \\
\hline Inflammatory complications of the surgical wound & $12(12.5 \%)$ \\
\hline Aacute pyelonephritis & $10(10.4 \%)$ \\
\hline Failure of ureterointestinal anastomosis & $4(4.2 \%)$ \\
\hline Total & $42(43.8 \%)$ \\
\hline
\end{tabular}

The frequency of postoperative acute pyelonephritis corresponded to the findings of other authors. Two $2(2.1 \%)$ patients died from early postoperative complications because of concomitant diseases (ischemic heart disease, myocardial infarction); thus, postoperative mortality in the early postoperative period was $4.2 \%$.

Among late postoperative complications (Table 3), we identified chronic pyelonephritis with chronic renal failure $(15.6 \%)$, urolithiasis $(12.5 \%)$, and a stricture of ureterointestinal anastomosis $(9.4 \%)$.

The average life expectancy of patients with bladder cancer on whom we operated was $786 \pm 150.5$ days. Chronic pyelonephritis with chronic renal failure detected in $15(15.6 \%)$ patients after one year after surgery was the most frequent late postoperative complication. The stricture of ureterointestinal anastomosis in 9(9.4\%) patients has been eliminated through relaparotomy and resection of anastomosis. The development of urolithiasis in $12(12.5 \%)$ patients after one year after surgery has required the implementation of contact lithotripsy and litholytic therapy. 
Table 3.

Late postoperative complications in patients with bladder cancer ( $n=96)$ in the period from 2005 to 2014

\begin{tabular}{|l|c|}
\hline \multicolumn{1}{|c|}{ Late postoperative complications } & $\begin{array}{c}\text { Number of } \\
\text { patients }\end{array}$ \\
\hline Chronic pyelonephritis with chronic renal failure & $15(15.6 \%)$ \\
\hline Urolithiasis & $12(12.5 \%)$ \\
\hline Stricture of ureterointestinal anastomosis & $9(9.4 \%)$ \\
\hline Total & $36(37.5 \%)$ \\
\hline
\end{tabular}

As a treatment for muscle invasive bladder cancer, radical cystectomy remains a highly morbid operation with complication rates of $40-60 \%$ and mortality rates as high as $9 \%$ in the first 90 days after surgery. ${ }^{[19,20]}$ Albisinni et al. ${ }^{[21]}$ have analyzed postoperative complications after laparoscopic radical cystectomy (LRC) and evaluated its risk factors in a large prospective cohort built by the ESUT across European centers involved in minimally invasive urology in the last decade. A total of 548 patients were available for final analysis, of which $258(47 \%)$ experienced early complications during the first 90 days after LRC. Infectious, gastrointestinal, and genitourinary were, respectively, the most frequent systems involved. Postoperative ileus occurred in $51 / 548(9.3 \%)$ patients. A total of $65 / 548(12 \%)$ patients underwent surgical re-operation, and 10/548 (2\%) patients died in the early postoperative period. Increased BMI $(P=$ $0.024)$, blood loss $(P=0.021)$, and neoadjuvant treatment $(P=$ $0.016)$ were significantly associated with a greater overall risk of experiencing complications on multivariate logistic regression. Long-term complications were documented in $64 / 548(12 \%)$, and involved mainly stenosis of the ureteroileal anastomosis or incisional hernias.

According to Gandaglia et al., ${ }^{[22]}$ among 1094 patients undergoing radical cystectomy, rates of overall complications, transfusions, prolonged length of hospitalization, readmission, and perioperative mortality were $31.1 \%, 34.4 \%, 25.9 \%$, $20.2 \%$, and $2.7 \%$, respectively. Body mass index represented an independent predictor of overall complications on multivariate analysis $(P=0.04)$. Baseline comorbidity status was associated with increased odds of postoperative complications, prolonged operative time, transfusion, prolonged hospitalization, and perioperative mortality. In particular, patients with cardiovascular comorbidities were 2.4 times more likely to die within 30 days following cystectomy compared to their healthier counterparts $(P=0.04)$. Men had lower odds of prolonged operative time and blood transfusions $(P \leq 0.03)$. Finally, the receipt of a continent urinary diversion was the only predictor of readmission $(P=0.02)$.

Radical cystectomy patients $(n=2303)$ captured from NSQIP hospitals from January 1, 2006 to December 31, 2012 were analyzed by Lavallée et al. ${ }^{[23]} 1115$ (48\%) patients were over 70 years old and $1819(79 \%)$ were male. Median hospital stay was 8 days (IQR 7-13 days). 1273 (55.3\%) patients experienced at least 1 post-operative complication of which 191 (15.6\%) occurred after hospital discharge. The most common complication was blood transfusion $(n=875$; $38.0 \%$ ), followed by infectious complications with $218(9.5 \%)$ urinary tract infections, 193(8.4\%) surgical site infections, and $223(9.7 \%)$ sepsis events. $73(3.2 \%)$ patients had fascial dehiscence, $82(4.0 \%)$ developed a deep vein thrombosis, and $67(2.9 \%)$ died. Factors independently associated with the occurrence of any post-operative complication included: age, female gender, ASA class, pre-operative sepsis, COPD, low serum albumin concentration, pre-operative radiotherapy, preoperative transfusion $>4$ units, and operative time $>6$ hours $(P<0.05)$. Complications, transfusions, readmission, and perioperative mortality remain relatively common events in patients undergoing radical cystectomy for bladder cancer.

\section{Conclusion}

Radical cystectomy with the Bricker ureterointestinal anastomosis allows us to obtain satisfactory functional results in the early and long-term periods after surgery, but the number of postoperative complications is still high. In our opinion, this is due to the imperfection of the analyzed ureterointestinal anastomosis, which is formed "end-to-side," that promotes the development of ureterointestinal reflux. A reduced valve function of the Bricker ureterointestinal anastomosis can cause severe complications, such as kidney stones, recurrent pyelonephritis, and renal insufficiency. In this regard, the development of a new method for the urethra anastomosis with the tubular intestinal segment has important value.

\section{Competing interests}

The authors declare that they have no competing interests.

\section{References}

1. Izmailov AA Risk factors for development, prognosis, and treatment selection of bladder cancer. ScD Thesis. Ufa, 2014. [Thesis in Russian]

2. Chissov VI, Alekseev BYa, Rusakov IG. National guidelines. Oncology. Moscow: Publishing House "GEOTARMedia"; 2012. [Manual in Russian].

3. Charyshkin AL, Matorkin DA. Surgical treatment of patients with bladder cancer. Ulyanovsk Biomedical Zhurnal. 2015;4:8-13. [Article in Russian].

4. Abol-Eneim H. Ghoneim MA. Further clinical experience with the ileal W-neobladder and a serous-lined extramural tunnel for orthotopic substitution. Br J Urol. 1995;76(5):558-64.

5. Bassi P, Ferrante GD, Piazza N, Spinadin R, Carando R, Pappagallo G, et al. Prognostic factors of outcome after radical cystectomy for bladder cancer: a retrospective study of a homogeneous patient cohort. J Urol. 1999;161(5):1494-7. 6. Deliveliotis C, Papatsoris A, Chrisofos M, Dellis A, Liakouras C, Skolarikos A. Urinary diversion in high-risk elderly patients: modified cutaneous ureterostomy or ileal conduit? Urology. 2005;66(2):299-304.

7. Farnham SB, Cookson MS. Surgical complications of urinary diversion. World J Urol. 2004;22(3):157-67.

8. Ferlay J, Autier P, Boniol M, Heanue M, Colombet M, Boyle P. Estimates of the cancer incidence and mortality in Europe in 2006. Ann Oncol. 2007;18(3):581-92.

9. Fulda S, Vucic D. Targeting IAP proteins for therapeutic intervention in cancer. Nat Rev Drug Discov. 2012;11(2):109-24. 
10. World Health Organization (WHO) Consensus Conference on Bladder Cancer, Hautmann RE, Abol-Enein H, Hafez K, Haro I, Mansson W, Mills RD, et al. Urinary diversion. Urology. 2007;69(1 Suppl):17-49.

11. Hautmann RE1, Volkmer BG, Schumacher MC, Gschwend JE, Studer UE. Long-term results of standard procedures in urology: the ileal neobladder. World J Urol. 2006;24(3):305-14.

12. Jemal A, Siegel R, Xu J, Ward E. Cancer statistics, 2010. CA Cancer J Clin. 2010; 60(5):277-300.

13. Lawrentschuk N, Colombo R, Hakenberg OW, Lerner SP, Månsson W, Sagalowsky A, et al. Prevention and management of complications following radical cystectomy for bladder cancer. Eur Urol. 2010;57(6):983-1001.

14. Nagele U, Kuczyk M, Anastasiadis AG, Sievert KD, Seibold J, Stenzl A. Radical cystectomy and orthotopic bladder replacement in females. Eur Urol. 2006;50(2):249-57

15. Stein JP1, Skinner DG. Radical cystectomy for invasive bladder cancer: long-term results of a standard procedure. World J Urol. 2006;24(3):296-304

16. Stenz A, Nagele U, Kuczyk M, Sievert K-D, Anastasiadis A, Seibold J, et al. Cystectomy - Technical Considerations in Male and Female Patients. EAU Update Series. 2005; 3(3):138-46. 17. Wood DN1, Allen SE, Hussain M, Greenwell TJ, Shah PJ. Stomal complications of ileal conduits are significantly higher when formed in women with intractable urinary incontinence. J Urol. 2004;172(6 Pt 1):2300-3.

18. Yossepowitch O, Dalbagni G, Golijanin D, Donat SM,
Bochner BH, Herr HW, Fair WR, Russo P. Orthotopic urinary diversion after cystectomy for bladder cancer: implications for cancer control and patterns of disease recurrence. J Urol. 2003;169(1):177-81.

19. Aziz A, May M, Burger M, Palisaar RJ, Trinh QD, Fritsche HM, et al. Prediction of 90-day mortality after radical cystectomy for bladder cancer in a prospective European multicenter cohort. Eur Urol. 2014; 66(1):156-63

20. Shabsigh A, Korets R, Vora KC, Brooks CM, Cronin AM, Savage C, et al. Defining early morbidity of radical cystectomy for patients with bladder cancer using a standardized reporting methodology. Eur Urol. 2009; 55(1):164-74.

21. Albisinni S, Oderda M, Fossion L, Varca V, Rassweiler $\mathrm{J}$, Cathelineau $\mathrm{X}$,et al. The morbidity of laparoscopic radical cystectomy: analysis of postoperative complications in a multicenter cohort by the European Association of Urology (EAU)-Section of Uro-Technology. World J Urol. 2016;34(2):149-56.

22. Gandaglia G, Varda B, Sood A, Pucheril D, Konijeti R, Sammon JD, et al. Short-term perioperative outcomes of patients treated with radical cystectomy for bladder cancer included in the National Surgical Quality Improvement Program (NSQIP) database. Can Urol Assoc J. 2014; 8(910):E681-7.

23. Lavallée LT, Schramm D, Witiuk K, Mallick R, Fergusson D, Morash C, et al. Peri-operative morbidity associated with radical cystectomy in a multicenter database of community and academic hospitals. PLoS One. 2014; 9(10):e111281. 